\title{
Urdimento
}

Revista de Estudos em Artes Cênicas

E-ISSN: 2358.6958

\section{Espacialidade travesti: habitat de gênero e práticas topográficas de corpos trans nas artes da cena brasileira}

\author{
Dodi Tavares Borges Leal
}

\section{Para citar este artigo:}

LEAL, Dodi Tavares Borges. Espacialidade travesti: habitat de gênero e práticas topográficas de corpos trans nas artes da cena brasileira. Urdimento, Florianópolis, v. 2 , n. 38, ago./set. 2020.

DOI: http:/dx.doi.org/10.5965/14145731023820200003

Este artigo passou pelo Plagiarism Detection Software | iThenticate 
Espacialidade travesti: habitat de gênero e práticas topográficas de corpos trans nas artes da cena brasileira

Dodi Tavares Borges Leal ${ }^{1}$

Resumo

O artigo trata de interrogar os processos poético-topográficos nas artes cênicas a partir dos paradigmas espaciais instaurados pelas corporalidades transgêneras na cena brasileira recente. A reflexão põe em tensão os fenômenos de performatividade do espaço (Mostaço, 2016) e de performatividade transgênera (Leal, 2018b) buscando entender traços de habitat de gênero nas artes contemporâneas. A espacialidade travesti é então pensada a partir de configurações cênicas provocativas suscitadas por modos atitudinais de proteção e criação de gênero no ambiente. Neste sentido, a partir de incitações de processos criativos recentes, e da noção de racismo ambiental (Santos et al., 2016), analisamos as categorias da passabilidade, da reclusão e do cisplay como possíveis modos de violência ambiental às transgeneridades.

Palavras-chave: Arte e espacialidade. Estudos cênicos de gênero. Topografia corporal. Transgeneridades.

\title{
Transvestite spatiality: gender habitat and topographic practices of trans bodies in the Brazilian performing arts
}

\begin{abstract}
The article tries to interrogate the poetic-topographical processes in the performing arts from the spatial paradigms established by transgender bodies in the recent Brazilian scene. The reflection puts in tension the phenomena of space performativity (Mostaço, 2016) and transgender performativity (Leal, 2018b), seeking to understand gender habitat traits in contemporary arts. The transvestite spatiality is then thought from provocative scenic configurations raised by attitudinal modes of protection and creation of gender in the environment. In this sense, from the incitement of recent creative processes, and the notion of environmental racism (Santos et al., 2016), we analyze the categories of passability, confinement and cisplay as possible modes of environmental violence to transgenderities.
\end{abstract}

Keywords: Art and spatiality. Theatrical gender studies. Body topography. Transgenderities.

1 Profa. Dra. Adjunta do Centro de Formação em Artes e do Instituto de Humanidades, Artes e Ciências da Universidade Federal do Sul da Bahia (UFSB). Doutora em Psicologia Social pelo Instituto de Psicologia da Universidade de São Paulo e Licenciada em Artes Cênicas pela Escola de Comunicações e Artes da Universidade de São Paulo. dodi@ufsb.edu.br 
Bacamarte aprovava esses sentimentos de estima e compaixão, mas acrescentava que a ciência era a ciência, e que ele não podia deixar na rua um mentecapto.

(O Alienista - Machado de Assis)

Como que a performatividade de gênero se inscreve no espaço social? A epígrafe acima, retirada do romance $O$ Alienista de Machado de Assis, nos apresenta a problemática ficcional desta obra em torno da interveniência da ciência em determinar a retirada de sujeitos da sociedade em decorrência a toda sorte de desvios subjetivo-sociais entendidos sob a categoria da loucura. Com a incursão dos estudos de gênero no campo das artes, deixando de ser um campo restrito às áreas jurídicas e médicas, nos vemos diante de novos questionamentos da produção cênica que levam em conta o impacto da subjetividade na produção e na recepção do espaço.

Produções teatrais e no campo da performance recentes (Leal, 2018a) têm se dedicado à reflexão sobre a seguinte questão: quais espacialidades o corpo trans pode habitar? Vemos que tais processos levam em conta não apenas os parâmetros de gênero na produção artística, isoladamente, mas recorrem à uma profunda revisão das prerrogativas colonizadoras de gênero nas artes cênicas (Leal e Rosa, 2020), ligadas à cisnormatividade.

Para além do importante debate sobre a inclusão de corpos trans nos contextos produtivos e receptivos da cena, entendemos que há a necessidade de se pensar em uma espacialidade travestivisando a reconfiguração dos dispositivos cisnormativos do espaço físico e psíquico de criação performativa. Por um lado teríamos a pergunta: como que as transgeneridades formam e são formadas nos espaços privados e públicos? Por outro lado, poderíamos interrogar: poderiam os espaços privados e públicos transicionar gênero na medida em que são ocupados por pessoas transgêneras?

Se a noção de conflito leva, por vezes, à criação de aspirações utópicas ou articulações políticas irrefletidas, a performance topográfica, imbuída de caráter tectônico, desregulariza sistemas arraigados pela 
ação cênica. As iniciativas iludidas que encontram conforto na denominação "sem fronteiras" não dão conta de expressar e transformar os abismos e isolamentos que configuram as relações de indivíduos hoje. Desprovidas dos saberes marginais do entre, das liminaridades, dos contornos e do trânsito polinizador como ecodinâmicas antropológicas de existir em cena, as pedagogias "sem fronteiras" padecem sobre si mesmas porque carecem das geologias sociais que definem subjetividades a partir de nivelamento de terras. Ao contrário, por estar profundamente marcadas de uma veia econômica neoliberalista de livre circulação, as pedagogias "sem fronteiras" parecem deslizar sobre superfícies planas e culturas uniformes. (Leal, 2019, p.26).

Este texto visa interpretar como as práticas topográficas de corporalidades trans nas artes da cena brasileira suscitam a configuração de habitats de gênero. Partimos do levantamento de paradigmas espaciais matemáticos e físicos para compreender sua interposição às estruturas subjetivas em seus exercícios em ambientes públicos e privados. Buscamos, em seguida, refletir sobre o exercício estético de produção e leitura da teatralidade de gênero no espaço, tendo em vista modos de proteção de pessoas trans às violências sociais. Por fim, montamos um quadro dos traços topográficos das corporalidades trans nas artes da cena brasileira.

Pretendemos avaliar de que modo a performatividade do espaço (Mostaço, 2016) se estabelece em função da performatividade transgênera (Leal, 2018b), procurando refletir tópicos recorrentes em produções cênicas recentes onde observamos configurações de habitats de gênero. Considerando que "espaço, tempo e mundo são noções históricas, circunstanciadas em função de certas características que as atravessam” (Mostaço, 2016, p. 105), e levando em conta o processo social de produção e recepção estética das transgeneridades (Leal, 2018b), perguntamos: com quais frações de espaço se conjuga o tempo poético das transgeneridades em cena? Observamos que temos em perspectiva que os estudos vigentes sobre a performatividade cênica do espaço não consideram suficientemente as construções sociais em sua concretude, tanto no âmbito privado como público. Neste sentido, almejamos aqui indiciar a expansão dos estudos de espacialidades a partir das corporalidades - ao passo que articulamos, 
então, a concretude performativa do espaço enquanto regulação social das relações da vida humana.

Para um olhar atento a esta questão, precisamos nos perguntar: há trânsito no intransitável? Quais as tensões e saberes provocados a partir da vivência psicossocial de reclusão? Quais os contornos rueiros do gênero? De que forma podemos modificar os contornos do espaço habitativo de gênero a partir de um exercício contrassexual (Preciado, 2017)? De quais disposições atitudinais de gênero se necessita para se proteger do espaço? Quais são os espaços dos quais precisamos nos proteger? Com quais empenhos subjetivos se promove uma modificação de gênero em suas espacialidades cênicas? Ler a performatividade de gênero no espaço subjetivo é o mesmo que ler o espaço social da performatividade de gênero? Ora, estaria o espaço do gênero entre o social e a subjetividade?

\section{Espaço físico, espaço psíquico. Espaço estético, espaço de gênero}

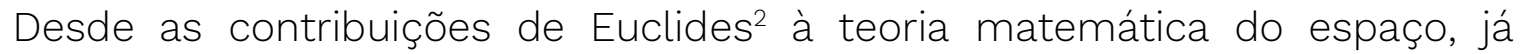
podemos observar a sua imbricação aguda com a subjetividade humana: "os gregos viram que os conhecimentos geométricos não poderiam depender da experiência ou da evidência sensorial, pois uma e outra nunca nos permitiriam entrar em contato com pontos, retas e planos, meras abstrações"3. Ora, se há elementos importantes para interpretar a vida e, ainda, os mesmos não estão, digamos, presencializados na experiência, a atividade abstrata ao passo que os produz, influi na sua própria percepção. Vejamos como que Einstein (1991, p. 112) se refere à origem psicológica da noção de espaço:

\footnotetext{
2 Euclides, geômetra grego (século III a.C.).

3 Texto "Euclides e a geometria" do Caderno Ilustradíssima do jornal Folha de São Paulo de 1 de agosto de 2010. Disponível em: http://www1.folha.uol.com.br/fsp/ilustrissima/il0108201001.htm, acesso em 7/3/2018 às 14h41, Praia Grande - Brasil.
} 
A origem psicológica da noção de espaço, ou da necessidade desta noção, não é tão manifesta como poderia parecer em razão de nossos hábitos de pensar. Os antigos geômetras tratam de objetos criados pela mente (reta, ponto, superfície), mas não do espaço como tal, como o fez mais tarde a geometria analítica.

Se não é nova a atividade de formar e de ler o espaço a partir da atividade mental, somente no pensamento moderno do século XX a subjetividade tornouse chave decisiva para tratar do espaço. É justamente a física einsteiniana que demonstrou com extrema perspicácia que a recepção é a proveniência que determina a relativização das noções de espaço e de tempo. Ou seja, ao mesmo tempo que, segundo a teoria da relatividade geral, o tempo difere para cada ente de acordo com o lugar que ocupa no espaço (por conta da adoção de diferentes sistemas referenciais), a própria noção absoluta do espaço é posta em xeque. De fato, a física e a astrofísica contemporâneas têm conjecturado veementemente possibilidades radicais de compreensão dos determinantes de formação e relação das matérias ${ }^{4}$.

Ora, o fato de não podermos dimensionar razões de grandezas tão distantes da percepção cotidiana não diminui o grau de relação da subjetividade com a formação do espaço. No entanto, podemos dizer que "nas escalas humanas, as geometrias convergem para padrões euclidianos"5. Neste sentido, na sensibilidade comum há uma assimilação palpável das grandes forças físicas que tende a reduzir as infinitudes a sentidos concretos, conhecidos ou não. E o que podemos dizer, por sua vez, dos arquétipos identitários ocidentais milenares de gênero (homem e mulher) e sua relação com a concretude de sua experiência no espaço social tendo em vista a performatividade de gênero (cis e trans)? Bem, provocamos, como fissura e teoria, uma epistemologia crítica social de gênero, onde a experiência espacial de gênero equivale à expressão e às possibilidades em

4 Hawking e Mlodinow (2005) nos apresentam o grande rol de novas ideias advindas desde a Teoria da Relatividade de Einstein: viagem no tempo; curvatura do espaço; a noção conjugada de espaço-tempo; infinitude do universo; a possibilidade da existência de infinitos universos: a ideia de multiverso; etc.

5 Texto "Euclides e a geometria" para o Caderno Ilustradíssima da Folha de São Paulo de 1 de agosto de 2010. Disponível em: http://www1.folha.uol.com.br/fsp/ilustrissima/il0108201001.htm. Acesso em: 7 mar. 2018, às 14h41, Praia Grande - Brasil. 
que ela se apresenta tendo em vista o parâmetro normativo: com passabilidade cis e sem passabilidade cis. Sendo uma atividade que instaura no espaço concreto tanto a inalcançabilidade identitária de gênero como a estrutura atitudinal da performatividade de gênero, a expressão de gênero reduz grandezas sociais a parâmetros observáveis pela experiência cotidiana.

Este é o fundamento espacial de uma modalidade de opressão que com muita frequência recai sobre pessoas transgêneras: a escala ou a régua. Estamos falando aqui da medida espacial de diferenciação performativa das transgeneridades com relação aos seus conteúdos identitários de masculinidades e/ou de mulheridades. Como possível correlato ao fenômeno de diferenciação dos corpos trans em escala/régua, o colorismo é a forma perversa de diferenciação dos corpos negros. Em ambos os casos temos o Estado ocidental como portador legítimo dos parâmetros de definição de gênero e étnico-racial. Lembremos que, no caso brasileiro, as medidas do IBGE (do quarto quartil do século XX) de medição dos diversos fenótipos de negritude não visou a princípio o combate ao racismo estrutural, mas sua perpetuação conjuntamente com o embranquecimento genocida latente da população deste país. Ora, no caso das transgeneridades, reiteramos o que já comentamos aqui: a diferenciação de pessoas trans em nada contribui para fomentar a compreensão e o respeito à diversidade das transgeneridades. Novamente, muitas vezes negligenciada por nomenclaturas desviantes de sexualidade que se sedimentaram no vocabulário atual do Brasil (bicha, sapatão, etc.), as formas trans são alvo de diferenciação sobretudo tendo como paradigma a transexualidade como condição hegemônica das transgeneridades. A escala perceptiva que se aventa para medição do grau de aproximação que a expressão de um corpo trans tem com o modelo de transexualidade tem por trás a própria cisnormatividade que fundamenta a criação psiquiátrica e epidemiológica da categoria transexual. Depreendemos daí a aberrante diferenciação de pessoas trans (a expressão "trans e travestis"): criada pelo Estado para denotar com legitimidade institucional, para que não haja dúvida, sobre quem é mais trans do que quem. 
E usamos aqui escala como uma medida de espaço que tem a régua como um instrumento paradigmático. Ou seja, o próprio conceito que aventamos aqui de forma alguma cai em uma armadilha, a qual ele próprio visa denunciar. Ora, ao afirmar que a diferenciação das atitudes expressivas das transgeneridades sempre esteve sob o controle do Estado brasileiro na formulação conjugativa "trans e travestis" e sob a égide da transexualidade, não pretendemos, ao mesmo tempo, dizer qual o termo mais preciso para tratar. Ou seja, a escala não é mais escala que a régua nem a régua é mais régua que a escala. Ambos os termos (régua e escala), e cada um deles, são provenientes de uma mesma tratativa de criar parâmetros objetivos da percepção subjetiva do espaço. Da mesma forma, ambos os termos (trans e travestis), e cada um deles, são provenientes de experiências diversas de resistência à cisnormatividade, ou seja, configuram uma mesma tratativa expressiva de criar parâmetros espaciais concretos para a percepção subjetiva adjacente à experiência das transgeneridades. Em trabalhos anteriores (Leal, 2018a; 2020) observamos que a vivência concreta das transgeneridades na contemporaneidade opera na alternância indisciplinar da performance de gênero em oposição à escala disciplinar da performance de gênero.

Em março de 2018 o Supremo Tribunal Federal (STF) brasileiro promulga decisão que visa desburocratizar a vida institucional de pessoas trans neste país. Incorrendo a erros diversos (como ainda diferenciar pessoas trans em diversas categorias), considera-se uma decisão progressista porque, ao contrário do histórico PCIScológico da noção genitalizante das transgeneridades, passou-se a considerar como oficial o reconhecimento de que há pessoas trans que transgenitalizam ou fazem faloplastia e há outras pessoas trans que não realizam qualquer tipo de procedimento cirúrgico ou hormonal. No entanto, talvez uma das maiores contribuições desta decisão foi retirar da esfera judicial e médicopsicológica a mediação legitimadora das transgeneridades. A extinção da necessidade de laudos e de processo judicial para retificação do nome civil e do gênero nos documentos é realmente algo fundamental para começarmos a romper o domínio hegemônico histórico das áreas da saúde e do direito sobre as transgeneridades. 
Podemos imaginar como que às próximas gerações as condições de dignidade de gênero estarão mais favoráveis. No entanto, herdamos uma história de opressão e vidas que padeceram deste CIStema e não poderão ser revividas. Lembradas, sempre! E é sob o reinado histórico do paradigma de régua e escala que a decisão progressista do STF ${ }^{6}$ se dá. Se fosse possível conjugar em camadas as formas opressivas e as formas progressistas de vivência espacial da expressão de gênero, veríamos que, de fato, elas sempre coexistiram. Basta pensarmos nas estratégias concretas inventadas por pessoas trans para lançar-se (ou não) sobre as possibilidades de recepção de gênero.

\section{Modos estéticos protegidos de colocação espacial das transgeneridades}

Há basicamente três formas de colocação espacial, em modo protetivo, das transgeneridades com relação às condições cisnormativas hegemônicas de leitura de gênero: a passabilidade, a reclusão e o cisplay. Trata-se de recursos poéticos aos quais se recorre para fazer frente às opressões sofridas por pessoas gênerodesobedientes. A primeira, a passabilidade, se relaciona às tecnologias de aderência expressiva normativa em relação à identidade de gênero para a qual uma pessoa transicionou. A matéria épica de desmontagem e montação presente nas configurações monstras são formas insurgentes de ruptura com padrões dramáticos de passabilidade cis; sempre visamos estender esta discussão para atitudes indisciplinares de desobediência de gênero. A segunda, reclusão, diz respeito às configurações de delimitação espacial da transição de gênero. Abaixo discutiremos alguns aspectos da reclusão com relação às performances transgêneras tendo em vista uma análise dos processos coloniais. A terceira, cisplay, trata das tecnologias de aderência expressiva normativa em relação ao

${ }^{6}$ Até 2020, ano da pandemia da covid-19 no Brasil, o STF nunca teve um/a ministro/a trans e a referida decisão, assim como todos os direitos conquistados por pessoas trans neste país sempre foram assinados por pessoas cis. Almejamos que as formas de reconhecimento social contemplem condições em que a reciprocidade possa se dar entre pares e não somente entre pessoas pertencentes a diferentes grupos. Para reflexões em mais detalhes sobre a estética trans pensada a partir do contexto da pandemia, ver Leal (2020). 
gênero definido compulsoriamente ao nascer. Abaixo comentaremos como as atividades de cisplay se dão entre pessoas trans. Por agora é importante frisar: nos três casos percebemos implicações de gênero da relação entre subjetividade e o espaço, tanto no que se refere à produção como à leitura.

Em pesquisa realizada por Santos (et al., 2016) a respeito das diversas facetas de opressão vividas por populações caiçaras que habitam o Litoral Sul de São Paulo, aventa-se o termo racismo ambiental para demonstrar como que há uma estrutura social que cria e mantém vulnerabilidades políticas tendo como base o ataque a determinadas circunscrições étnico-raciais no espaço. Ora, o termo ambiente provém da área Psicologia Ambiental, crescente desde os anos 1990, e, segundo os próprios autores, é adequado por dar uma precisão estratégica à luta comunitária destes grupos em sua relação com o espaço que habitam:

Defendemos que a noção de racismo ambiental fornece uma linguagem compatível para compreender os conflitos socioambientais em curso na região, ao mesmo tempo em que se configura como um instrumento de advocacy capaz de mobilizar as comunidades e de influenciar atores políticos institucionais na formulação de políticas públicas que efetivem e garantam os direitos dos povos que vivem na floresta. (Santos et al., 2016, p. 5).

Talvez pudéssemos articular o termo transfobia ambiental para referirmonos às condições espaciais em que se instauram as formas de opressão vividas por pessoas transgêneras. No entanto, defendemos uma revisão do termo transfobia por conta da carga patológica atribuída ao opressor ao qual esta expressão opera. O intuito de denotar o caráter político e social da violência às desobediências de gênero caminha junto com a inutilização do radical fobia já que muito antes de ser um problema clínico, estamos lidando com uma configuração moral: a opressão. Assim, por ora nos referimos à ideia de que passabilidade, reclusão e cisplay configuram o que talvez possamos chamar de violência ambiental às transgeneridades.

Tratemos da reclusão como matéria poética de composição espacial da performatividade transgênera. Precisamos apresentar dois lados do fenômeno: o 
dramático e o lírico. Provavelmente apenas a primeira forma se associe a um verdadeiro exercício de opressão, e a segunda a um deliberado ato estético. Neste sentido, de um lado temos a noção de reclusão que talvez mais se ligue à ideia de detenção ou de auto-aprisionamento no qual o foco da delimitação espacial está em retirar-se (ou ser retirado/a) dos meios de convivência social por conta da condição trans. Nesta configuração há uma evidente atuação intersubjetiva na qual se entende ou que não há possibilidades de acolhimento de um processo de transição de gênero ou que a única forma de admissibilidade da pessoa trans seja um ponto final neste processo. Em ambos os casos desta primeira forma de reclusão há o paradigma do processo transexualizador que restringe não apenas um meio de caminho da modificação corporal mas, sobretudo, preconiza parâmetros de finalidade cisnormativos destas possibilidades de modificação corporal.

Por sua vez, a segunda forma, a lírica, talvez mais se aproxime com a ideia de instalação presente no teatro pós-dramático, e na arte contemporânea de maneira geral. A instalação é uma arbitração estética investigativa sobre o espaço na qual se aventam possibilidades formais e temáticas de se tratar da subjetividade no ambiente. De acordo com Lehmann (2007) a lírica presente na teatralidade pósdramática traz consigo o efeito quadro ou molduragem como recurso de tratamento dos elementos da matéria no espaço. O autor sublinha que esta operação compreende um exercício de precisão escultural das gestualidades. Provavelmente o exemplo instalativo mais comum em que pessoas trans se inscrevem no espaço hoje são as redes sociais. Ainda que saibamos da potência épica dos textões na contemporaneidade, tomando apenas a molduragem lírica como exercício de elaboração da vivência trans no espaço, as instalações associadas aos perfis denotam a ambivalência das categorias de presença e de ausência na vida social. Obviamente a habitação das redes sociais não se refere a uma atividade espacial empreendida apenas por pessoas transgêneras hoje. No entanto, se associarmos ao exercício de reclusão como forma de proteção espacial de vivência de pessoas trans, as redes sociais se oferecem como 
molduragens ambientais à disposição para as pessoas que não são acolhidas em sua transição ou devir (sem ponto final) da sua performatividade transgênera.

Se retomarmos a primeira forma de reclusão e relacionarmos a ela uma análise dos processos coloniais nos quais se inscrevem as transgeneridades, podemos verificar que enquanto nos países do Sul como o Brasil e a América Latina as formas épica, lírica e dramática das transgeneridades coexistem, nos países do Norte apenas a forma dramática das transgeneridades é uma opção. Em outras palavras, a reclusão como forma protetiva de transição de gênero que tem como paradigma o processo transexualizador está presente tanto nos países colonizadores ${ }^{7}$ como nos países que foram colonizados; no entanto, nos países colonizadores somente há a reclusão como recurso institucional de vivência das transgeneridades. Tanto que é muito comum em países do Norte a literal retirada das instituições (escola, trabalho, família, etc.) de pessoas que se submetem ao processo transexualizador, durante uma faixa de anos que pode variar entre 1 a 4 anos, e seu posterior retorno a estes mesmos espaços. Já em países como o Brasil tanto há este modelo quanto as formas resistentes que não se submetem a este condicionamento, onde localizamos a epicidade travesti. É preciso ressaltar que a categoria queer cada vez mais incidente nos países do Norte tem uma matriz diaspórica, ou seja, somos nós (do Sul, do CU do mundo) que construímos historicamente as formas anticoloniais de desobediência de gênero, da qual a forma travesti é simultaneamente protagonista e resultante. Aprendemos com Pêdra Costa que é preciso trazer de volta o CU ou KU ao queer e devolver o kuir para a rua de onde nunca deveria ter saído: "A intenção é trazer a discussão e a teoria queer de volta para o seu lugar de origem, lugar este que nunca deveria ter abandonado - a rua." (Costa apud Gadelha, 2017, p.451).

Caceres (2017) comenta que mesmo países como a Áustria que não chegou a ter diretamente colônias na América, Ásia ou África, por pertencer à rede de países europeus imperialistas, se beneficiou indiretamente desta configuração geopolítica de dominação. 


\section{Práticas topográficas de corpos trans nas artes da cena}

A repressão normativa do cu fez com que esta zona corporal se constituísse como o principal espaço de reclusão e de resistência da sexualidade na ocidentalidade. Da mesma forma, o gênero encontra nos processos anais um correspondente paradigmático das dinâmicas de formação espacial, tanto no que se refere às geometrias padronizadoras como no que se refere às matemáticas indisciplinares. Nos concentraremos, então, a tomar a condição habitativa do cu como forma contrassexual épica de ocupação espacial das transgeneridades:

Que cool, que cool é esse?

Quem quer cair dentro dele?

Primeiro põe um pé, o outro

Depois cai dentro

Mas que cool, aconchegante

Parece um acampamento.

Primeiro põe um pé, o outro

Depois cai dentro

Mas aqui tem tanto espaço

Tá mais pra um apartamento.

(Dedo Nucué - Linn da Quebrada ft. Mulher Pepita, álbum Pajuba). ${ }^{8}$

Continuemos a tratar da rua como configuração épica fundamental de vivência das transgeneridades no espaço social em oposição à forma dramática da reclusão. A oposição entre o espaço privado e o espaço público não é de maneira alguma secundária nesta discussão. A vivência rueira das transgeneridades, a qual sintetizamos como travestis, ora aporta um estigma

8 Dedo Nucué de Linn da Quebrada ft. Mulher Pepita trata das práticas contrassexuais como espaço de resistência. Disponível em: https://www.youtube.com/watch?v=NtUtgkkNtFg. Acesso em: 8 mar. 2018 às 9h24, Praia Grande - Brasil. 
espacial dramática das desobediências de gênero, ora tem a rua como matéria de elaboração épica da resistência enquanto coralidade e coletividade. Por outro lado, a reclusão, ao passo que pode viabilizar formas líricas contestatórias das vivências trans, como as instalações poéticas e comunicativas das redes sociais, se baseia em sua hegemonia à forma dramática de transexualização dos corpos. Não à toa, a dialética entre a cura e a loucura relaciona a humanização à condição patológica de pessoas trans. De fato, precisamos tensionar o aspecto neoliberal presente na reclusão como forma biopolítica de inscrição espacial das performances de gênero desobedientes.

A vivência de reclusão transexualizadora é uma forma de performance biopolítica do gênero entre muros que se pretende humanizadora. Seja por meio dos dispositivos de retirada ou de instalação em rede social, a vivência trans contemporânea que tem a inscrição espacial pela reclusão se regimenta em dinâmicas psicossociais da vida condominial. "O apelo à vida em forma de condomínio baseia-se, como os antigos leprosários e hospícios, na promessa de recuperação e reconstrução da experiência perdida. A antiga noção de cura não tem outro sentido que não a de reencontro de um lugar." (Dunker, 2015, p. 52).

\footnotetext{
A lógica do condomínio tem por premissa justamente excluir o que está fora de seus muros; portanto, no fundo, não há nada para pensar na tensão entre esse local murado e seu exterior. Também não há muito a pensar na tensão intramuros, uma vez que, como observamos, a única área de real convivência pública é o playground. O espaço já é concebido e vivido como um falso universal. Por isso, os que vivem fora estão sem lugar, sem terra, sem teto, sem destino. E os que vivem dentro estão demasiadamente implantados em seu espaço, seu lugar e sua posição. A psicanálise nos ensina a reconhecer com suspeita tais produções sociais, que acenam com uma região de extraterritorialidade protegida, um espaço abrigado onde se concentraria a realização do prazer retinto de liberdade. Aprendemos com a experiência neurótica que a montagem de uma fantasia possui três tempos, nos quais se distribui o cálculo neurótico do gozo. (Dunker, 2015, p. 52-53).
}

Se de um lado podemos mencionar novamente as redes sociais como um playground oferecido às pessoas trans pelo CIStema genocida para que se gere a ilusão de pertencimento, ainda que reclusiva, devemos levar em conta que também no espaço público as transgeneridades se expõem a toda sorte de 
violência. Tanto a passabilidade como o cisplay, que não ocorrem apenas em ambientes fechados, quando acontecem na rua acabam por proteger as pessoas trans de uma ampla gama de ataques discursivos e corporais, executados ou sutis. Até mesmo o amor nós travestis aprendemos na rua em forma de violência:

Aprendi amar nos cantos

Rapidinho pela rua

Nem tirava toda a roupa

Quase nem ficava nua.

(Tomara - Linn da Quebrada, álbum Pajuba). ${ }^{9}$

Como artifício épico de oposição à violência ambiental às transgeneridades, sugerimos a curvatura e a esquina como mecanismos travestis de desmontagem do cartesianismo do gênero no espaço (de linhas retas, cisnormativas, dramáticas).

Ora, se falarmos do cisplaye suas formas de aderência expressiva normativa em relação ao gênero definido compulsoriamente ao nascer poderemos também perceber neste caso a paradoxalidade da conjugação violência-resistência. Cisplay é uma corruptela de cosplay (termo em inglês que abrevia a expressão costume play, e se refere à caracterização de personagens conhecidos). Na contemporaneidade, o cisplay é o novo armário. E já aprendemos com a epistemologia do armário de Sedgwick (2007) que a reclusão pode tanto ter o efeito de esconder/fugir para eliminar a diferença como o efeito de esconder/fugir para proteger a diferença, para fazê-la brotar. Assim, de acordo com a autora, tanto antes como depois da revolta de Stonewall o armário foi um recurso emblemático para tratar da matéria sensível ${ }^{10}$ do segredo da dissidência sexual vivido no ambiente familiar privado, o quarto, o cisplay é uma configuração espacial que leva o segredo à rua, a todos os lugares onde a pessoa desobediente

9 Tomara de Linn da Quebrada. Disponível em: https://www.youtube.com/watch?v=pQmOVhCoE4w. Acesso em: 8 mar. 2018 às 9h28, Praia Grande - Brasil.

10 Ver os conceitos de pensamento simbólico e pensamento sensível articulados na Estética do Oprimido de Boal (2009). 
de gênero está ou quer estar. Denotamos a intenção do querer estar como fundamental para compreensão do cisplay como modo protetivo: muitas pessoas trans recorrem a este artifício hoje para poupar-se de interpelações em ambientes diversos como os espaços burocráticos, médicos, a compra de passagem terrestre e aérea, etc. Obviamente há situações em que a pessoa trans se esforça para fazer cisplay mas sua transgeneridade está tão à flor da pele que não há mecanismo que a esconda. De uma forma ou de outra, estar no espaço público é sempre um desafio à pessoa trans que está saindo de qualquer armário, seja ele cisplay ou não:

Então eu sigo em frente

E vou com meu cabelo desgrenhado

E meus olhos levam um lápis mal passado

Não quero mais voltar

A ser um ser humano adestrado.

Quer saber? O armário está muito apertado.

Então eu sigo em frente

E vou com meu cabelo desgrenhado

E meus olhos levam um lápis mal passado

Não quero mais voltar

Pra essa história em que ser livre é ser errado

E viver como animal engaiolado.

(Desgrenhado - Banda Alameda dos Anjos, álbum Por mais simples que seja). ${ }^{11}$

O termo animal engaiolado de Desgrenhado exprime com precisão a articulação de duas facetas da opressão às transgeneridades: a reclusão e a bestialidade. Vejamos, por fim, um belo exemplo de armário no qual brotam vidas

11 A música Desgrenhado da Banda Alameda dos Anjos retrata a violência aos corpos transfemininos e negros tomando o cabelo desgrenhado como um gesto de resistência. No clip da música, a pesquisadora participa ao lado da vocalista Dani Policastro e Agatha Mont, ambas mulheres trans negras. O clip foi lançado junto com uma série de vídeos de entrevistas com pessoas gênero-desobedientes, incluindo um comigo e outro com Agatha. As gravações foram feitas em outubro de 2016; em fevereiro de 2017, Agatha foi assassinada em Itapevi aos 26 anos. Disponível em: https://www.youtube.com/watch?v=fqPIUqOpFeA. Acesso em: 28 fev. 2018 às 19h28, Praia Grande - Brasil. 
desobedientes de gênero. No trecho musical a seguir percebemos literalmente como que a oxigenação indisciplinar de gênero pode promover a proliferação de vidas resistentes às normatividades sociais:

\author{
Seguem passos certos \\ Escritos em linhas tortas \\ Dentro de armários suados \\ No cio de seu desespero \\ Um olho no peixe \\ Outro no gato \\ Trancados arranham portas (dores!) \\ Nos maxilares, cânceres, tumores \\ vyados que proliferam \\ Em locais frescos e arejados \\ De mendigos a doutores \\ Cercados por seus pudores [...]
}

(Submissa do 70 dia - Linn da Quebrada, álbum Pajuba). ${ }^{12}$

\section{Considerações finais}

Não por acaso recorremos a subscrições da produção musical recente de pessoas trans para pensar as práticas topográficas de corpos trans nas artes da cena brasileira. O trabalho da cantora Linn da Quebrada, por exemplo, não pode ser compreendido estritamente como domínio da produção fonográfica. Suas investidas de palavra e de cena são altamente performativas e incitam reinvenção em subjetividades espaciais da cena brasileira.

Ao tratarmos aqui de práticas espaciais de proteção das transgeneridades e ao relacionarmos estes aspectos com o conteúdo estético das corporalidades da cena, verificamos que as configurações de habitats de gênero incitam mudanças

12 A música Submissa do 70 dia de Linn da Quebrada trata do espaço de crescimento e de existência de dissidências sexuais, as quais se condicionam em função da repressão cristã destes corpos. Disponível em: https://www.youtube.com/watch?v=Kfjhie6Y5Qc. Acesso em: 8 mar. 2018 às 8h25, Praia Grande Brasil. 
epistemológicas de presença topográfica. Neste sentido, a construção cênica de espacialidades travestis expande a ideia de que a transição de gênero acontece apenas com pessoas. Com esta revisão, o espaço utópico da cisgeneridade, ganha contornos cartográficos como pistas de gênero que modulam as geologias artísticas da cena para além das cruéis violências ambientais às transgeneridades.

\section{Referências}

ASSIS, Machado de. O Alienista. São Paulo: Ática, 1998.

BOAL, Augusto. A Estética do Oprimido - reflexões errantes sobre o pensamento do ponto de vista estético e não científico. Rio de Janeiro: Garamond, 2009.

CACERES, Imayna. Anti*colonial fantasies. In: CACERES, Imayna. Mesquita, Sunanda. Utikal, Sophie (Orgs.). Anti*colonial fantasies: decolonial strategies. Vienna: Zaglossus, 2017.

DUNKER, Christian Ingo Lenz. Mal-estar, sofrimento e sintoma: uma psicopatologia do Brasil entre muros. São Paulo: Boitempo, 2015.

EINSTEIN, Albert. A Teoria da Relatividade Especial e Geral. São Paulo: Atlas, 1991. GADELHA, Kaciano. DeCUlonização e diásporas trans: uma entrevista com Sanni e Pêdra Costa. In: PeriódiCUS - Revista de estudos indisciplinares em gêneros e sexualidades. vol.1, n.7. Salvador: Grupo de Pesquisa CUS, Universidade Federal da Bahia, 2017.

HAWKING, Stephen. MLODINOW, Leonard. Uma nova história do tempo. Rio de Janeiro: Ediouro, 2005.

LEAL, Dodi. LUZVESTI: iluminação cênica, corpomidia e desobediências de gênero. Salvador: Devires, 2018a.

LEAL, Dodi. Performatividade transgênera: equações poéticas de reconhecimento recíproco na recepção teatral. Tese (Doutorado em Psicologia Social). Instituto de Psicologia da Universidade de São Paulo, 2018b.

LEAL, Dodi. Teatro do Oprimido Contemporâneo: performatividade e fronteiras. In: LEAL, Dodi. Teatra da Oprimida: últimas fronteiras cênicas da pré-transição de gênero. Porto Seguro: UFSB, 2019. 
LEAL, Dodi. A arte travesti é a única estética pós-apocalíptica possível? Pedagogias anticıStêmicas da pandemia. In: Pandemia Crítica, n.094. São Paulo: n-1 edições, 2020.

LEAL, Dodi. ROSA, André. Transgeneridades em performance: desobediências de gênero e anticolonialidades das artes cênicas. In: Revista Brasileira de Estudos da Presença, v.10, n.3, pp.1-29, 2020.

LEHMANN, Hans-Thies. Teatro Pós-Dramático. São Paulo: Cosac Naify, 2017.

LEPECKI, André. Coreo-política e coreo-polícia. In: Ilha - Revista de Antropologia. v.13, n.1-2, 2011.

MOSTAÇO, Edélcio. Espaço e performatividade. In: O Percevejo Online, v.8, n.1, p.103-111, 2016.

PRECIADO, Paul. Manifesto contrassexual. São Paulo: n-1 edições, 2017.

SANTOS, Alessandro de Oliveira dos. MASSOLA, Gustavo Martineli. SILVA, Luis Guilherme Galeão da. SVARTMANN, Bernardo. Racismo ambiental e lutas por reconhecimento dos povos de floresta da Amazônia. In: Global Journal of Community Psychology Practice, v.7, 2016.

SEDGWICK, Eve Kosofsky. A epistemologia do armário. In: Cadernos Pagu. n.28, janeiro-junho. Campinas: Núcleo de Estudos de Gênero - Pagu, Universidade Estadual de Campinas, 2007.

Recebido em: 30/06/2020

Aprovado em: 12/08/2020 